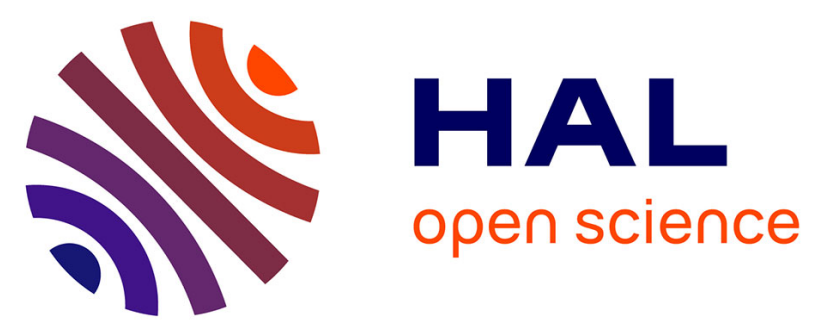

\title{
Effect on magnetic properties of inhomogeneous compressive stress in thickness direction of an electrical steel stack
}

H. Helbling, Abdelkader Benabou, Adrien van Gorp, Mohamad El Youssef, A. Tounzi, W. Boughanmi, D. Laloy

\section{- To cite this version:}

H. Helbling, Abdelkader Benabou, Adrien van Gorp, Mohamad El Youssef, A. Tounzi, et al.. Effect on magnetic properties of inhomogeneous compressive stress in thickness direction of an electrical steel stack. Journal of Magnetism and Magnetic Materials, 2020, 500, pp.166353. 10.1016/j.jmmm.2019.166353 . hal-03182776

\section{HAL Id: hal-03182776 https://hal.science/hal-03182776}

Submitted on 26 Mar 2021

HAL is a multi-disciplinary open access archive for the deposit and dissemination of scientific research documents, whether they are published or not. The documents may come from teaching and research institutions in France or abroad, or from public or private research centers.
L'archive ouverte pluridisciplinaire HAL, est destinée au dépôt et à la diffusion de documents scientifiques de niveau recherche, publiés ou non, émanant des établissements d'enseignement et de recherche français ou étrangers, des laboratoires publics ou privés. 


\title{
Effect on magnetic properties of inhomogeneous compressive stress in thickness direction of an electrical steel stack
}

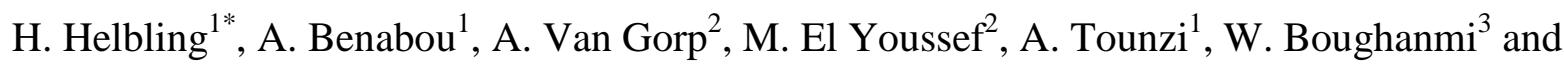
D. Laloy ${ }^{3}$

${ }^{1}$ Université de Lille, L2EP, 59000 Lille, France

${ }^{2}$ Arts et Métiers ParisTech-MSMP, 59000 Lille, France

${ }^{3}$ JEUMONT Electric, 59460 Jeumont, France

*Corresponding author e-mail: hugo.helbling@univ-lille.fr, Phone: +33 (0)362268 210

\begin{abstract}
The manufacturing processes of electrical machines may lead to significant degradation of magnetic core properties and therefore of the machine performance. Laminations are usually stacked and pressed which affects the magnetic properties and the iron losses. However, the influence of this step must be still investigated when large generators are considered. Indeed, in that case, the stator and rotor stacking process consists in assembling several stacks of electrical steel sheets separated by airvents. The surface of the airvent spacers represents about ten percent of the lamination surface of the magnetic circuit, implying, during the compaction process, an inhomogeneous stress distribution with significant local stresses. The present work deals with the experimental characterization of a lamination stack, including airvents, under compressive stress in the thickness direction. A mock-up has been designed and built-up to study magnetic properties of lamination stacks under pressing conditions corresponding to the industrial process.
\end{abstract}

Keywords: magnetic properties; iron losses; manufacturing process; compressive stress

\section{Introduction}

In order to increase the energy efficiency of high power electric machines, the reduction of losses is a key point. However, there still exist differences between the expected losses obtained from material models used in the design of the machines and those measured on the manufactured ones. One reason for these differences not considered in the material model is the impact of the manufacturing process on the magnetic core properties. To address this issue, the most commonly studied processes in the literature are the cutting, welding, pressing or shrink-fitting [1]-[5] . The effect of degradation due to cutting is mainly located at the 
cutting edges, whereas the welding may induce higher eddy current losses. When the stator is placed inside a housing, the shrink-fitting is relevant as it induces a mechanical stress gradient that impacts the magnetic properties.

The present work deals with the case of large generators for which the magnetic circuit is constituted of several stacks separated by airvents that are pressed together in the thickness direction of the laminations. To maintain the applied pressure, the whole magnetic circuit is then placed inside a steel cage that is usually welded on the outer diameter of the stator and/or clamped through end rings by axial screws. The impact of this step on magnetic properties of laminations has been investigated in some articles without considering the compressive stress distribution or by assuming that the stress distribution was homogeneous [5]-[7]. Other works, such as [8], computed the stress distribution within a toroidal sample by mechanical Finite Element (FE) study, in order to have the most homogeneous possible distribution of stress. All these works show that the compressive stress has an impact on the magnetic properties.

However, in the case of large generators, the compressive stress distribution in the magnetic core may be inhomogeneous because of the airvents spacers, implying significant inhomogeneous and localized stresses. In the literature, no work has addressed this problematic. The aim of this paper is to investigate the effect on magnetic properties of inhomogeneous compressive stress in thickness direction of a toroidal sample. An experimental mock-up has been developed to study the compressive stress distribution on magnetic properties of a $M 400-65 A$ electrical steel stack, because this steel grade is usually used for large generators. The experimental device was developed with the aid of mechanical FE study in order to analyze the stress distribution in the magnetic core.

This work presents several highlights. First, the developed mock-up enables to study the effect on magnetic properties of inhomogeneous compressive stress in thickness direction of an electrical steel stack which represents a practical industrial case in the presence of airvents that has not yet been studied in the literature. Second, inhomogeneous and homogeneous stress distributions obtained with and without airvents are precisely known by mechanical FE simulations. Third, the mock-up has been built-up to study magnetic properties of lamination stacks under parameters corresponding to industrial conditions. Fourth, the toroidal electrical steels were cut by the Wire Electrical Discharge Machining (WEDM) technique to reduce the impact of cutting on magnetic properties [9]. Moreover, it allows to have only the impact of pressing in order to avoid results like those in [8] where measured electrical steel losses are well above those given by the lamination grade, even without any compressive stress. Fifth, the obtained results were compared and validated with a reference measurement, including the repeatability analysis. Furthermore, measurements were made up to $4 \mathrm{MPa}$ for homogeneous stress distribution and up to $80 \mathrm{MPa}$ local stress for inhomogeneous stress distribution, with various sinusoidal magnetic field density waveform of frequencies from 5 $\mathrm{Hz}$ to $400 \mathrm{~Hz}$. The impact of compressive stress is not observed only on the total iron losses but also on hysteresis losses.

The paper is organized as follows. Part 2 describes the methodology of this work: the design of the mock-up with the mechanical FE study, the development of the mock-up and the experimental protocol that was followed. The air flux compensation method is introduced in Part 3. In Part 4, results and discussions about tests with homogenous and inhomogeneous 
stress distributions are given. Finally, in Part 5, the main conclusions of the study and future work are presented.

\section{Methodology and experimental mock-up}

\subsection{Methodology}

The methodology of this work is as follows. First, mechanical FE simulations are performed to design and develop an experimental mock-up that allows having homogeneous and inhomogeneous stress in the magnetic core. Then, the magnetic properties (constitutive law, iron losses) are measured under different levels of homogeneous and inhomogeneous compressions in the thickness direction. Finally, the impact of the compressive stress distribution on the magnetic properties is compared for different configurations.

\subsection{Geometry of the mock-up}

The mock-up is composed of a magnetic circuit, a primary and secondary windings and an axial compression system. As the compressive stress must be applied on the whole magnetic circuit area, two winding frames (Figure 1-d) are place on both sides of the magnetic circuit. A clamping screw is used in order to apply and maintain the stress on the magnetic core (Figure 1 -a). Finally, two PVC plate (Figure 1 -c) are added to improve the homogenization of the compressive stress and a force sensor (Figure 1-b) is inserted between one of the PVC plates and the head of the clamping screw to measure the force and better distribute the effort. Airvents (Figure 1-e) are added for the study of inhomogeneous stress distribution. In the homogeneous case, airvents plates (Figure 1-e) are removed. The whole geometry is presented in Figure 1 and a cross section view is presented in Figure 2.
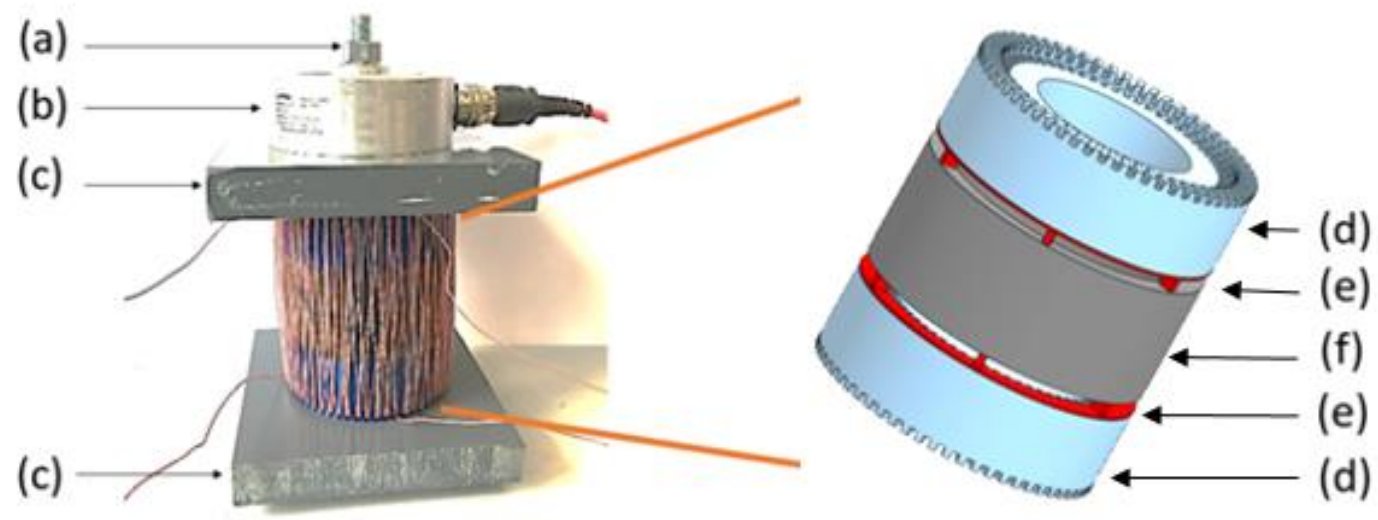

Figure 1. Experimental mock-up $-(\mathrm{a})=$ Clamping screw, $(\mathrm{b})=$ Force sensor, $(\mathrm{c})=\mathrm{PVC}$ plate,$(\mathrm{d})=$ Winding frame, $(\mathrm{e})=$ Airvents, $(\mathrm{f})=$ Laminated circuit $($ washer samples, outer diameter $=100 \mathrm{~mm}$, inner diametre $=86 \mathrm{~mm}$, height $=42 \mathrm{~mm}$ ) 


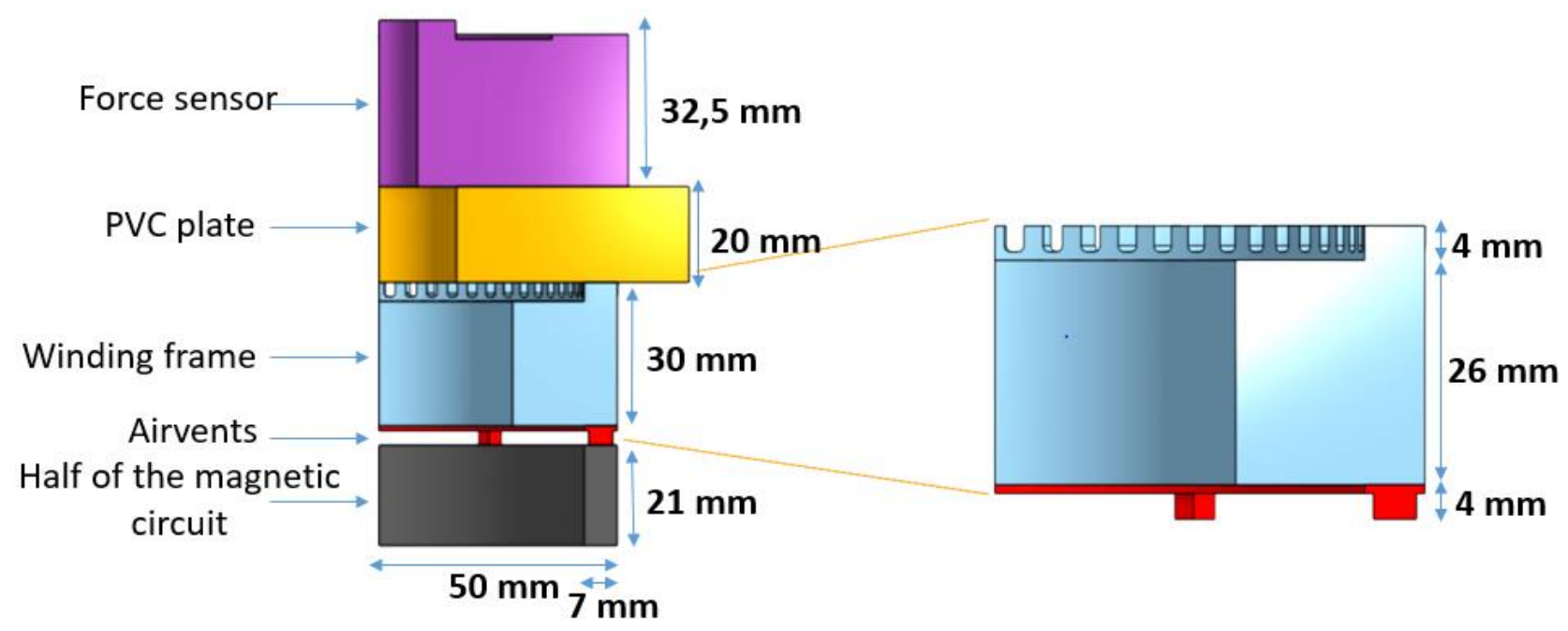

Figure 2. Mock-up cross section - Dimensions

\subsection{Design and specification of the mock-up}

To design the mock-up, mechanical FE simulations were firstly performed. Materials for the force sensor, the plates and the magnetic core previously described in Figure 1 are respectively: anodized aluminum, PVC and M400-65A. The material used for the winding frames is nonmagnetic and electrically non-conductive. It must allow transmitting accordingly the homogeneous and inhomogeneous stress distributions on the magnetic circuit, have sufficient compressive stress resistance and be easily machined. The FE mechanical simulations are performed on SimScale software [10]. The contacts between the different parts are modeled by Coulomb friction. For each contact, we have chosen a Coulomb coefficient of 0.5 . It is an arbitrary choice which voluntarily oversees the coefficient in order to be in the most unfavorable case, in particular for the contact between winding frames and the magnetic circuit. Moreover, to model the compressive stress application, a perpendicular force to the surface of the force sensor is applied. To build the mechanical model we consider one fourth of the device, according to the revolution axis, with symmetry planes as boundary conditions. Also, along the height of the device, a zero displacement boundary condition is set in the middle plane. Material parameters (Young's modulus, Poisson's ratio, density) are defined according to Table 1.

\begin{tabular}{|c|c|c|c|}
\hline Material & $\begin{array}{c}\text { Young's modulus } \\
(\mathrm{GPa})\end{array}$ & $\begin{array}{c}\text { Poisson's } \\
\text { ratio }\end{array}$ & $\begin{array}{c}\text { Density } \\
\left(\mathrm{kg} / \mathrm{m}^{3}\right)\end{array}$ \\
\hline Force sensor & 70 & 0,34 & 2700 \\
\hline PVC & 3 & 0,4 & 1500 \\
\hline Winding frame & 3,5 & 0,36 & 1250 \\
\hline Magnetic circuit & 211 & 0,29 & 7874 \\
\hline
\end{tabular}

Table 1. Material parameters for the FE mechanical simulations

Simulation results are presented in Figure 3. For more convenience, the stress level scale is set to $4 \mathrm{MPa}$ maximum to facilitate the reading but in practice, local stress reaches about 20 MPa. 

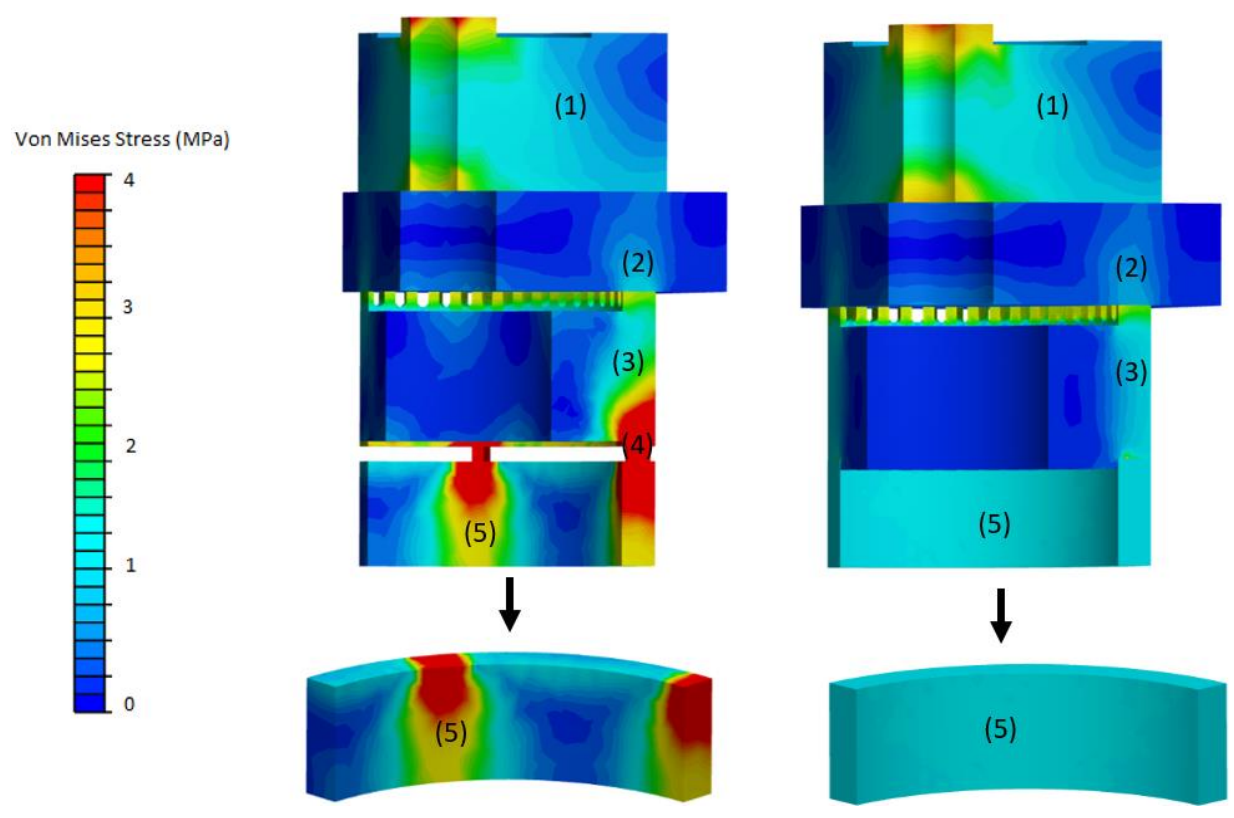

Figure 2. Von Mises Stress on the mock-up cross section (top) and on the magnetic circuit (bottom) for the inhomogeneous case (left) and the homogeneous case (right)

(1): Force sensor, (2): PVC plate, (3): Winding frame, (4): Airvents, (5): Magnetic circuit

To be representative of industrial conditions, height of studied magnetic core is the same as that of the stacks separated by airvents in stators of large generators (about $42 \mathrm{~mm}$ ). Similarly, the stress levels are representatives of those employed in the manufacturing process for these large generators. The electrical steel stack is composed of 65 toroidal electrical steel sheets of M400-65A, cut by WEDM with outer diameter of $100 \mathrm{~mm}$ and inner diameter of $86 \mathrm{~mm}$. The laminations were not annealed. Because of the winding frame design, the winding was realized by hand with 120 turns at the primary and 60 turns at the secondary.

\subsection{Validation of the mock-up}

The objective is to study the impact of compressive stress on the magnetic properties. It is necessary to have reference measurements on the magnetic properties of the core without stress and to validate that the mock-up gives reliable results in these conditions.

Therefore, two reference magnetic circuits composed of the same sheets were made, Figure 3. Magnetic measurements are made on MPG200D Brockhaus ring core tester. Measurements of magnetic field and induction are done in accordance with IEC 60404-4 and IEEE standard 393-1991 [11]. Moreover, intrinsically the repeatability of the ring core tester equipment is less than $0.1 \%$. However, in practice, accounting for the accuracy of the force sensor and the error introduced by the viscolesactic behavior of the winding frames, the observed repeatability for several levels of stress is less than $0.5 \%$. As this will be emphasized in the experimental results section, the effect of the normal stress is significantly higher than the repeatability error.Figure 4 shows the iron loss and the B-H normal curves, built from the $\mathrm{B}_{\max }\left(\mathrm{H}_{\max }\right)$ of centered hysteresis loops, for both magnetic circuits. Magnetic properties are similar for both magnetic circuits. For instance, the iron losses under sinusoidal 
magnetic flux density of $1.5 \mathrm{~T}$ (peak) and $50 \mathrm{~Hz}$ are $3.75 \mathrm{~W} / \mathrm{kg}$, which means that studied M400-65A electrical steel sheets respect their grade (and that the sample cutting did not affect significantly the material properties).

The different measurements conducted on the two reference circuits confirm that there is a negligible dispersion in the magnetic properties of the toroidal electrical steel sheets.

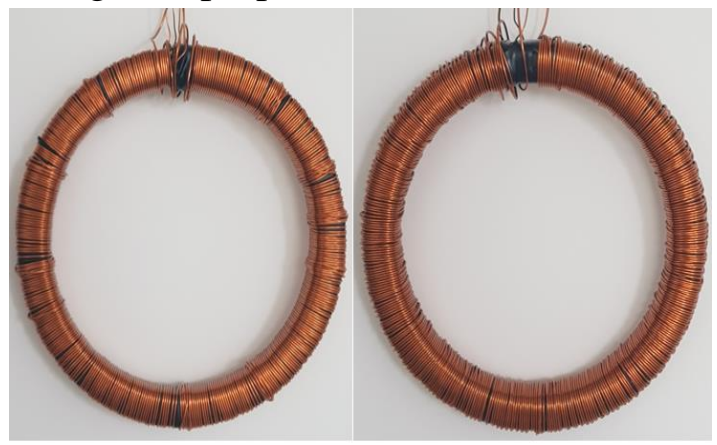

Figure 3. References magnetic circuits
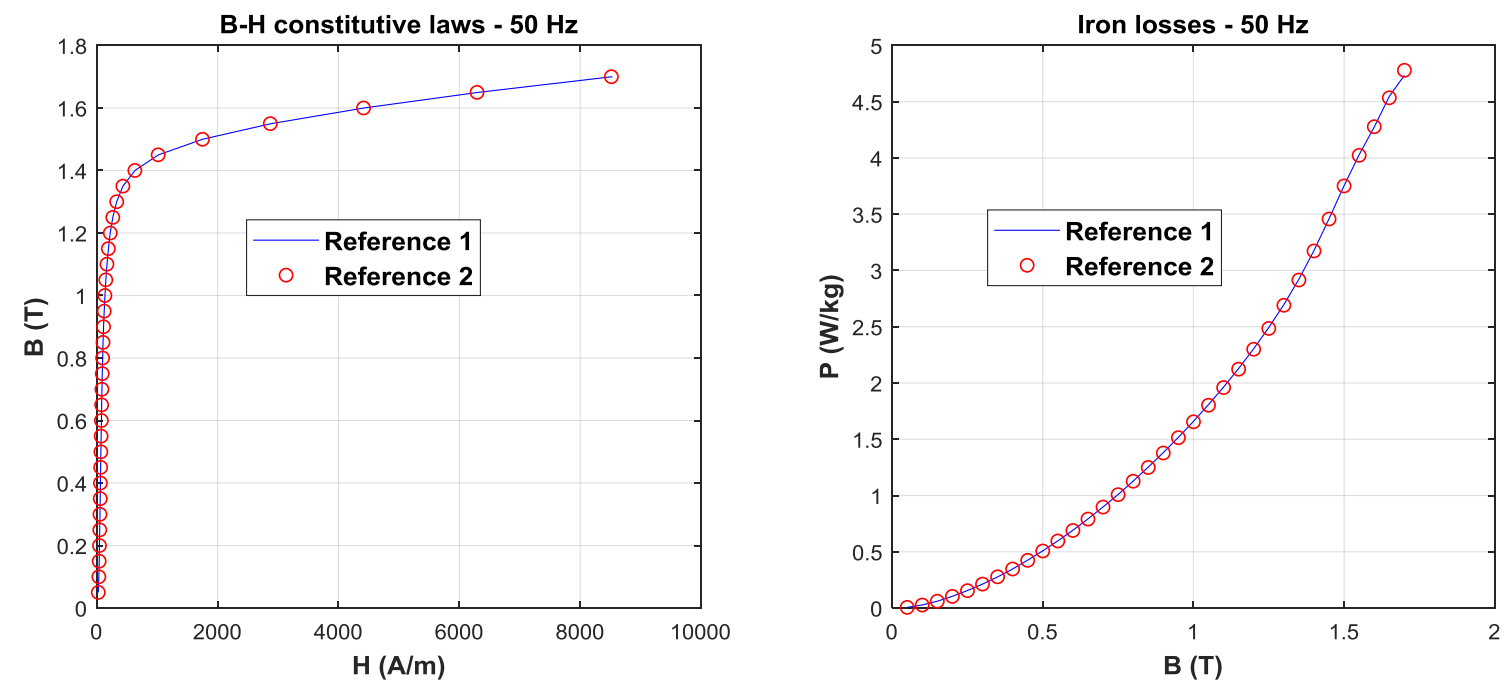

Figure 4. B-H curves (left) and Iron losses (right) of both reference magnetic cores

The next step deals with the comparison between these references and the mock-up circuit. First, magnetic circuits used for the mock-up and for the references have the same outer and inner diameter. Also, they were cut at the same time, with the same technique (WEDM) and come from the same lamination coil. Only the height and the windings are different. For the reference ring cores, a height of $15 \mathrm{~mm}$ has been chosen. The cross section is well above the one recommended by the standard. Concerning the windings, the mock-up circuitrequires the compensation of the air flux due to the use of winding frames. The best way to do this is to implement a compensation coil but, due to the complexity of the winding and of the mock-up shape, an approximated mathematical factor was implemented to compensate the air flux. First, as iron losses are related to the mass of the magnetic core which has been considered by the ring core tester, the air flux has no impact on it and results shown in Figure 5 validate our experimental mock-up concerning iron losses. Furthermore, Figure 6 (a) shows the comparison between B-H curves of the reference magnetic cores and of the mock-up, with and without air flux compensation. The compensation method gives very satisfactory results when comparing the B-H curve with air flux compensation to the reference measurement. Moreover, effect of the compressive stress on the B-H curve, Figure 6 (b), is higher than the remaining discrepancy after air flux compensation. We can therefore conclude on the reliability of the experimental mock-up. 


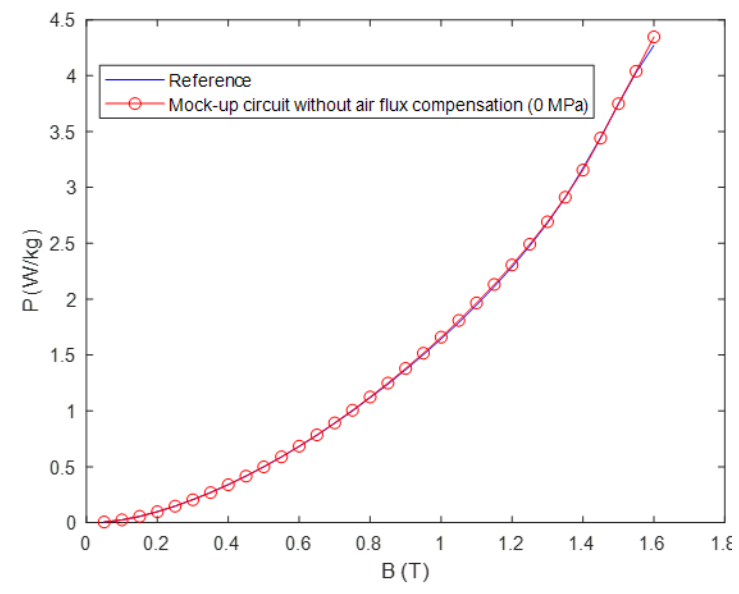

Figure 5. Iron losses comparison between reference and mock-up magnetic cores
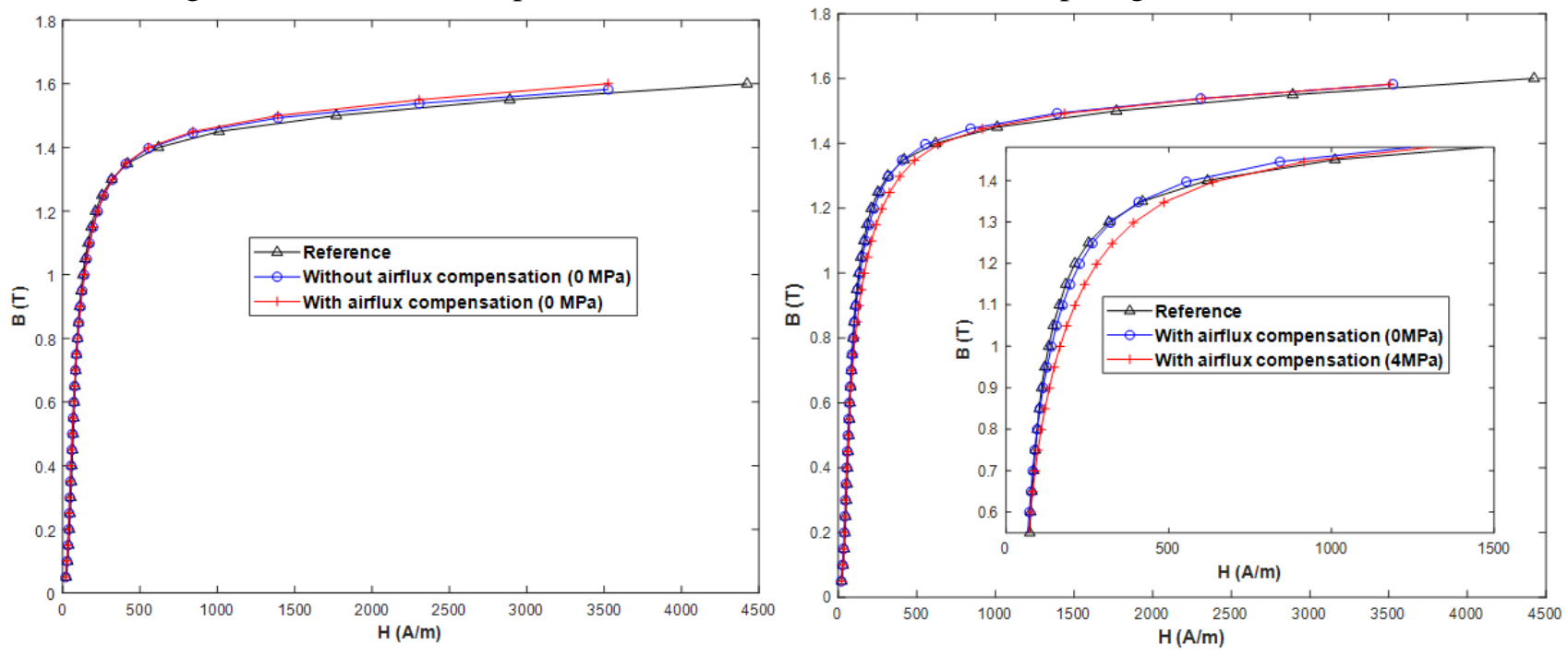

Figure 6. B-H curves with air flux compensation at $0 \mathrm{MPa}$ (a) and comparison of B-H curves at 0 $\mathrm{MPa}$ and $4 \mathrm{MPa}$ for homogenous compressive stress (b)

\section{Measurements, results and discussion}

\subsection{Measurements}

This part describes the measurement protocol, with an emphasizing on its key points. As previously mentioned, mechanical FE simulations were carried out to validate the stress distribution for both considered stress configurations (homogeneous and inhomogeneous) and the mechanical resistance.

The nonmagnetic material for the winding frames was chosen so that it can support high local stress, i.e. with a typical compressive resistance of about $110 \mathrm{MPa}$. However, for studied stresses, this material has viscoelastic behavior [12] that should be considered. Indeed, when the mock-up is compressed, stress level will sligthly decrease due to the viscoelasticity of the material. To reach the desired stress level, it requires to tighten the clamping screw a few times until the stress level is stable. Also, for magnetic field densities higher than $1.4 \mathrm{~T}$, the winding frames will heat up due to the current in the coils which will induce a greater stress on the mock-up magnetic core. Measurements were done with a fan 
cooling system to limit this effect. On the contrary, measurements on the reference magnetic circuits were carried out without the fan cooling system because these have no viscoelastic problem. Moreover, temperature of the reference magnetic circuit was less than $40^{\circ} \mathrm{C}$ during measurements.

In the homogeneous case, measurements were carried out for stress levels up to $4 \mathrm{MPa}$. In the inhomogeneous stress distribution (with airvent spacers) measurements were made with the same compressive forces as for the homogeneous case, which means that, even if the global pressure on the magnetic circuit is the same, the local stress in the vicinity of the airvent spacers reaches levels up to $80 \mathrm{MPa}$ in our case. This local stress is calculated analytically from the applied force divided by the area of the airvent spacers. Same results are obtained by FE simulations. Measuremeents have been observed to be repeatable in the elastic domain. Concerning the topology of the airvents spacers in the inhomogeneous stress distribution, the paper deals with the case presented in Figure 7.

Measurements were carried out from $0.05 \mathrm{~T}$ to $1.6 \mathrm{~T}$ for frequencies of $5 \mathrm{~Hz}, 25 \mathrm{~Hz}, 50$ $\mathrm{Hz}, 100 \mathrm{~Hz}, 150 \mathrm{~Hz}, 200 \mathrm{~Hz}$ and $250 \mathrm{~Hz}$. Moreover, measurements were carried out from 0.05 to $1 \mathrm{~T}$ at $400 \mathrm{~Hz}$. For the homogeneous stress distribution, tests are made at $0 \mathrm{MPa}, 1$ $\mathrm{MPa}, 2 \mathrm{MPa}, 3 \mathrm{MPa}$ and $4 \mathrm{MPa}$.

It must also be noted that the results shown in the following are considered for the representative lamination stack $(42 \mathrm{~mm})$ whatever the stress configuration case. In particular, for the inhomogeneous case, the global stress is obviously transmitted along the whole stack but locally there is a gradient between the extremities of the stack where the airvent spacers are placed. For more convenience, the presented results should then be seen as the global stack magnetic behavior.
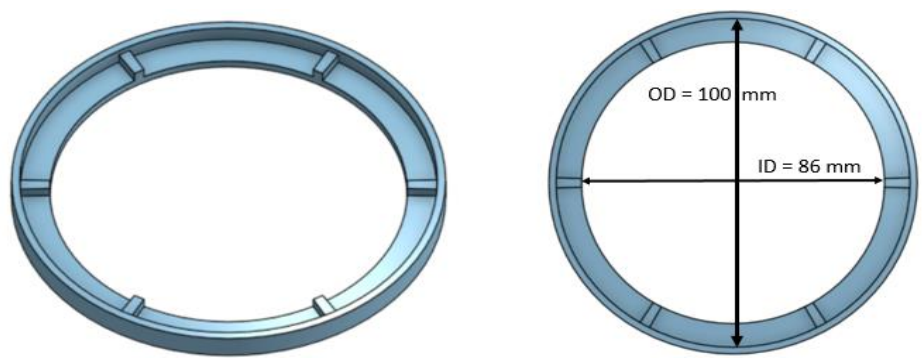

Figure 7- Layout of the airvent spacers

\subsection{Results and discussion}

First, the effect of different normal stress levels on the major hysteresis loops is given in Figure 9 at $50 \mathrm{~Hz}$ and $250 \mathrm{~Hz}$, showing modifications mainly in the knee regions. In Figure $10-(A)$ and Figure 10, the impact of the compressive stress on B-H curve is shown. We observe that the inhomogeneous case is, as expected, the most impacting one. This is mainly observable in the knee region of the curves. To further analyze this impact, Figure 11 - (A) and Figure $11-(B)$ show the required magnetic field depending on the magnetic induction, at $50 \mathrm{~Hz}$. For the other frequencies, the relative impact of the compressive stress on the B-H curve is globally the same as for $50 \mathrm{~Hz}$ each one of them. It is clear that the presence of the airvent spacers significantly increases the magnetic field necessary to reach induction levels higher than 0.6 T. Below 0.5 T, the impact of the compression is less 
significant and can, according to the stress distribution and the value of the global stress, increase or decrease the magnetic field. Rather than looking at the required magnetic field for a given induction, one can look at the reached magnetic induction for a given magnetic field. This corresponds to the same phenomena but it is interesting to note that the maximum relative decrease is up to $10 \%$ at $4 \mathrm{MPa}$ for the inhomogeneous case, which represents approximately $0.1 \mathrm{~T}$.
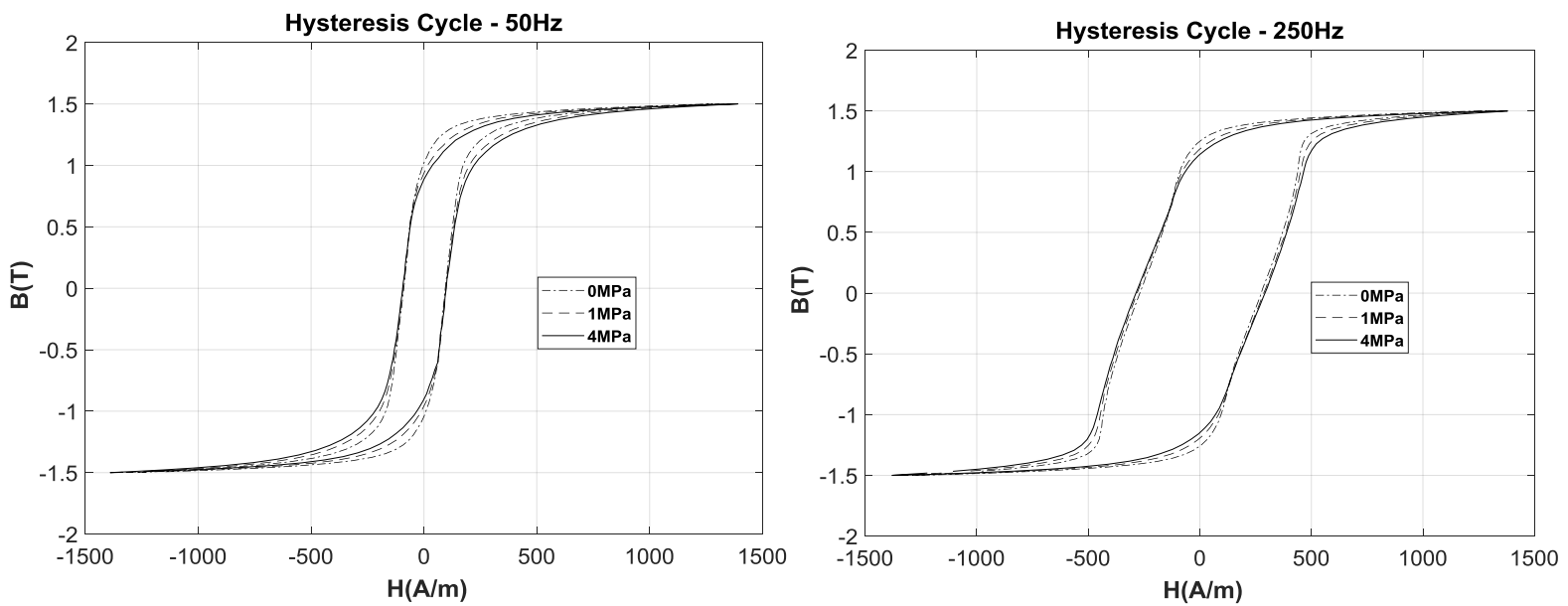

Figure 9 - Impact of compressive stress distribution on hysteresis cycles at $50 \mathrm{~Hz}$ and $250 \mathrm{~Hz}-$ Inhomogeneous distribution
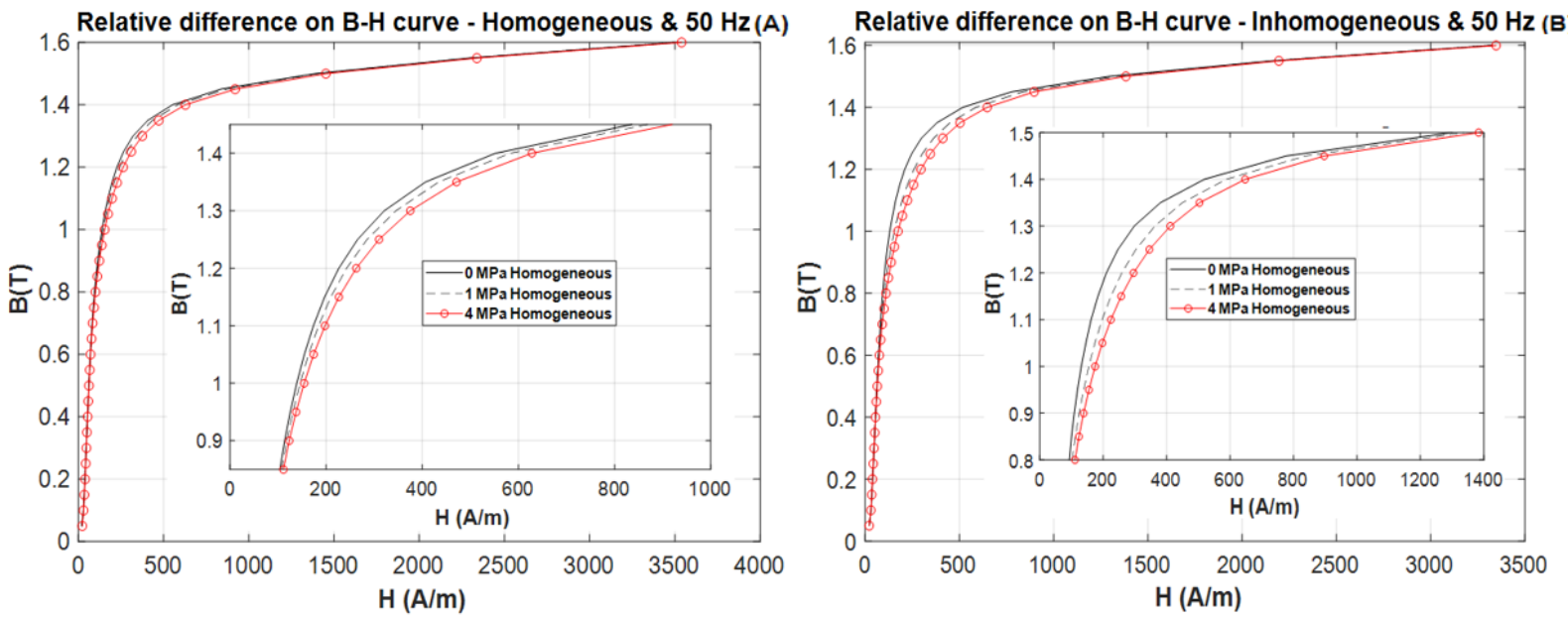

Figure 10 - Impact of compressive stress distribution on B-H curve - Homogeneous case (A) and inhomogeneous case (B) 

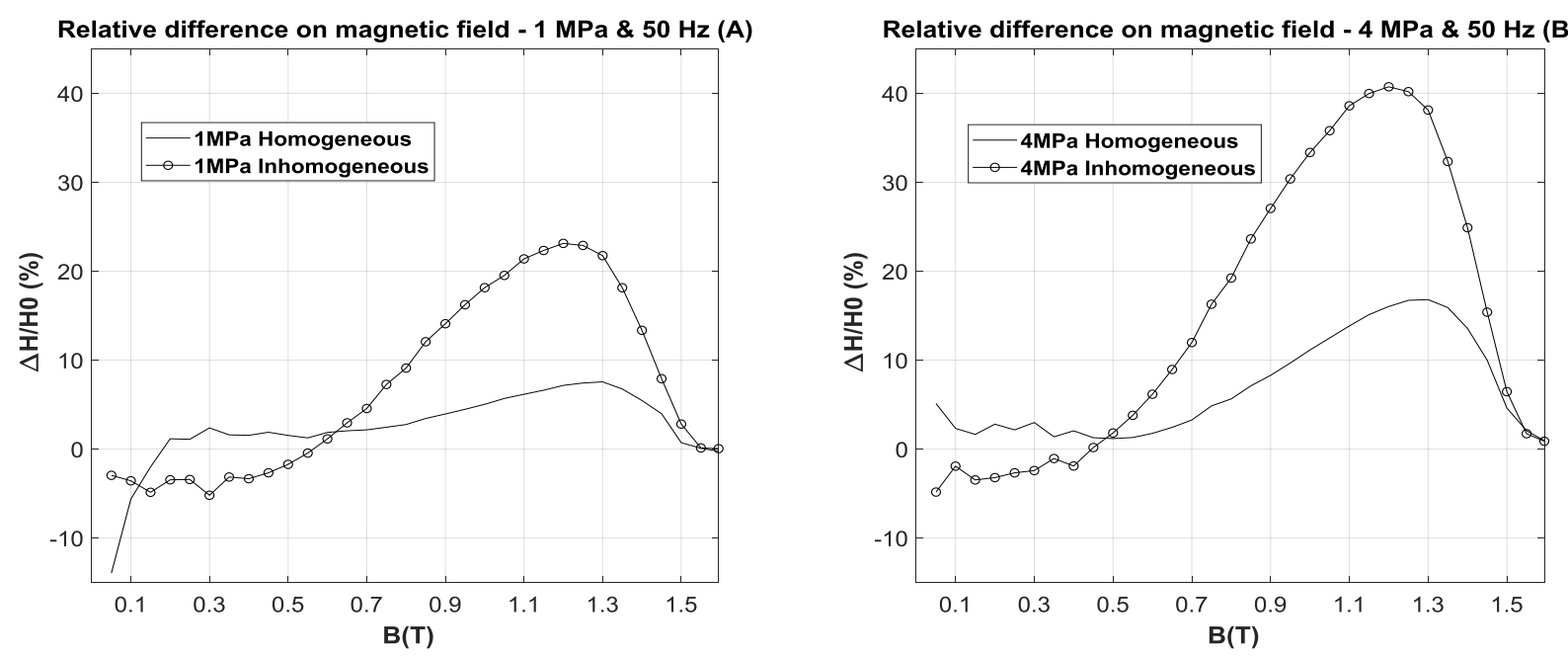

Figure 11 - Impact of compressive stress distribution on magnetic field

Moreover, we give the relative difference on iron losses between the configurations with and without compressive stress in Figure 12, $(A),(B),(C)$ and $(D)$.
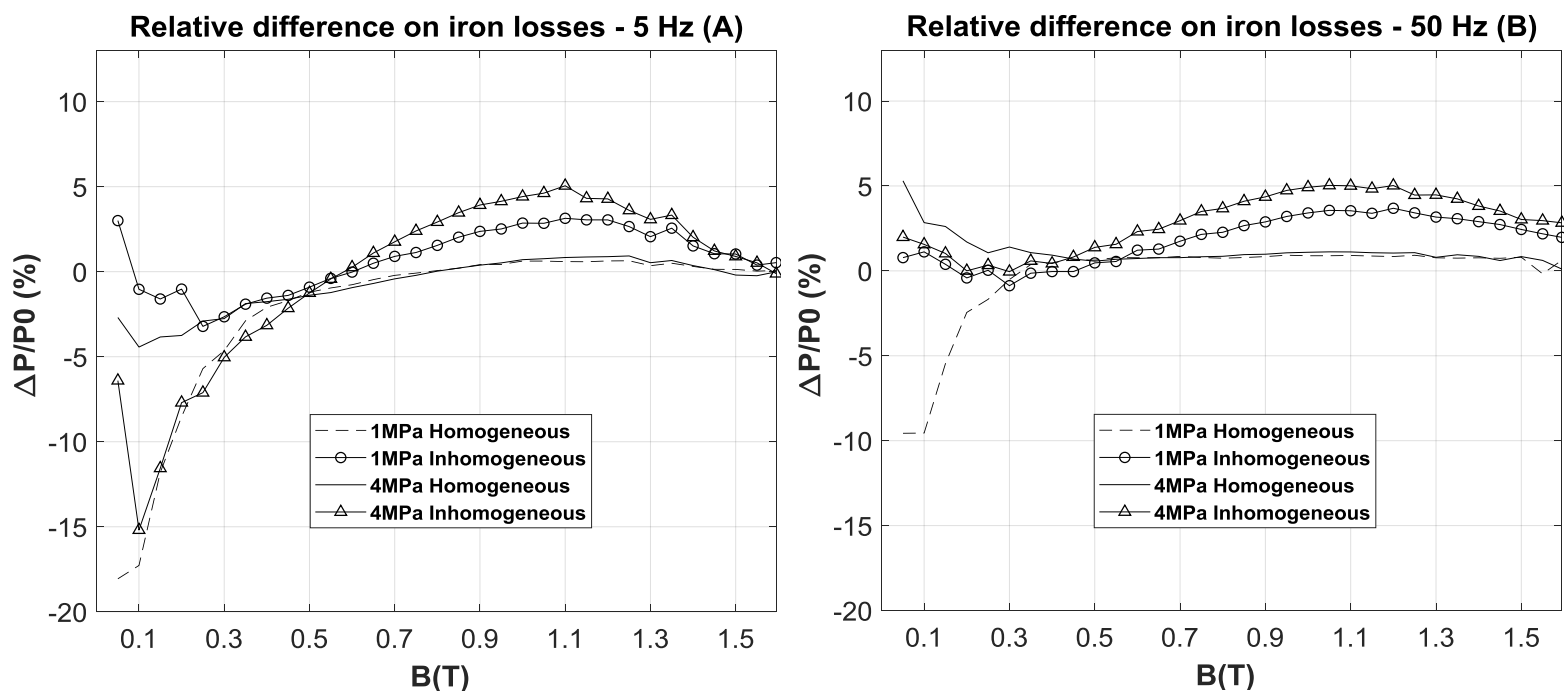

Relative difference on iron losses - $250 \mathrm{~Hz}$ (C)
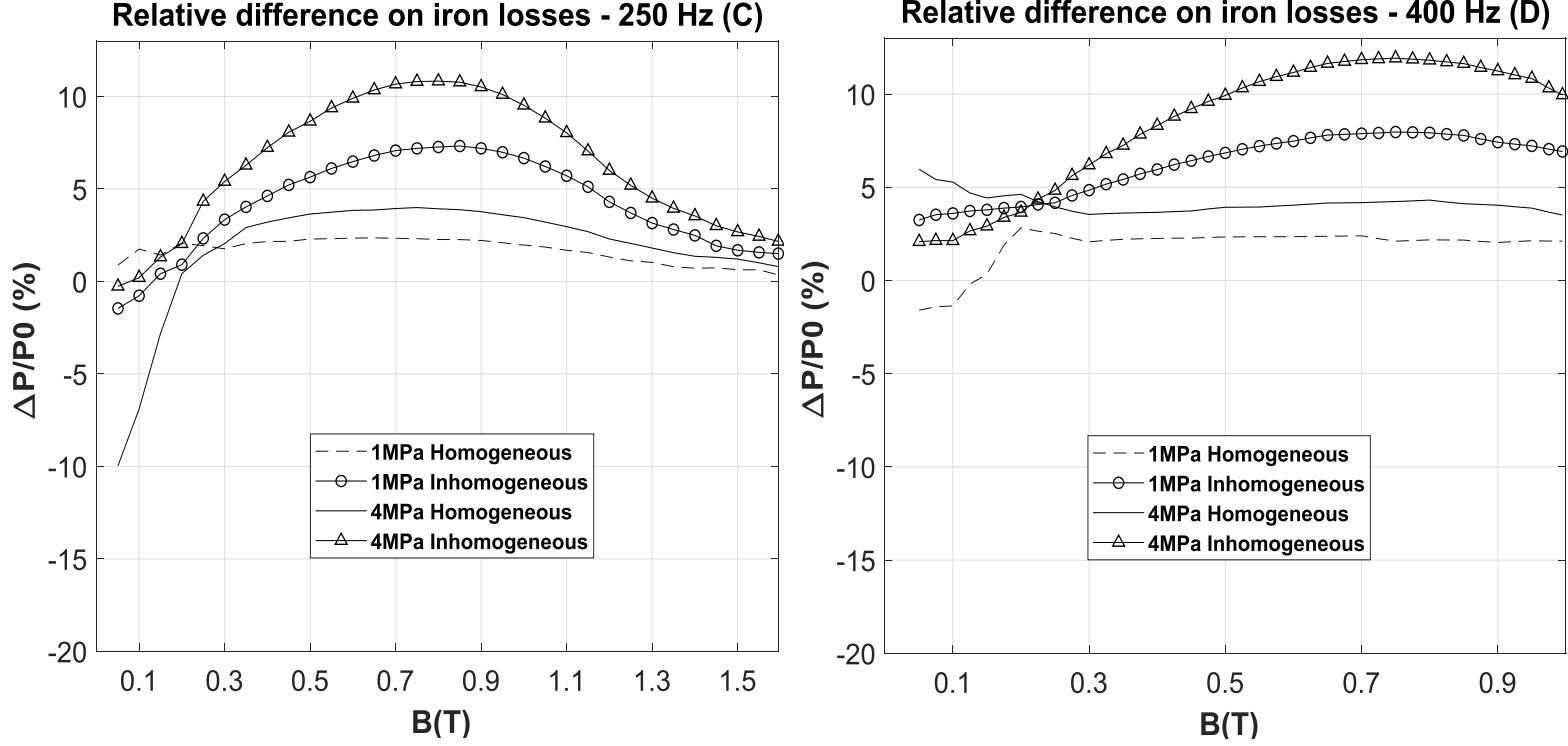
First, two magnetization regions can be considered with these results: average magnetization (below $\sim 0.5 \mathrm{~T}$ ) and high magnetization (above $\sim 0.5 \mathrm{~T}$ ). For the high magnetization region, which in accordance with the literature, the compressive stress leads to the iron losses increasing in the magnetic core. Moreover, the more compressive stress is significant, the more iron losses increase. Similarly, a significant increase of iron losses is observed at $250 \mathrm{~Hz}$ and $400 \mathrm{~Hz}$. However, for all studied frequencies, results show that inhomogeneous compressive stress distribution with the airvent spacers increases more significantly the losses than in the homogeneous case. In fact, its impact is up to five times higher for the inhomogeneous case, Figure $12-(B)$. When reaching saturation, the relative difference tends to decrease.

For the low and average magnetization regions, iron losses show a decrease in the homogeneous case at $1 \mathrm{MPa} / 50 \mathrm{~Hz}$ (Figure $11-(B)$ ) and this observation is even more pronounced at $5 \mathrm{~Hz}$ whatever the configurations (Figure $11-(A)$ ).

Previous figures reveal that the inhomogeneous compressive stress distribution induces a higher degradation on magnetic properties of the M400-65A magnetic core than a homogenous compressive stress distribution, due to significant local stress.

To further analyze these results, the evolution of the hysteresis losses is shown on Figure 13. We consider the classical losses as constant because at the studied pressure levels the electrical conductivity of the lamination is not modified. Also, there is no significant deformation of the magnetic circuit. However, the hysteresis losses are impacted significantly as illustrated in Figure 13. Considering that the relative difference on the hysteresis losses should not be modified with increasing frequency, we observe that the relative difference on the total losses still increases with the frequency (see for example Fig. 12-B and -C). This observation can be interpreted as the increase of the excess losses with the compressive stress. This is especially observed for average magnetic flux densities.

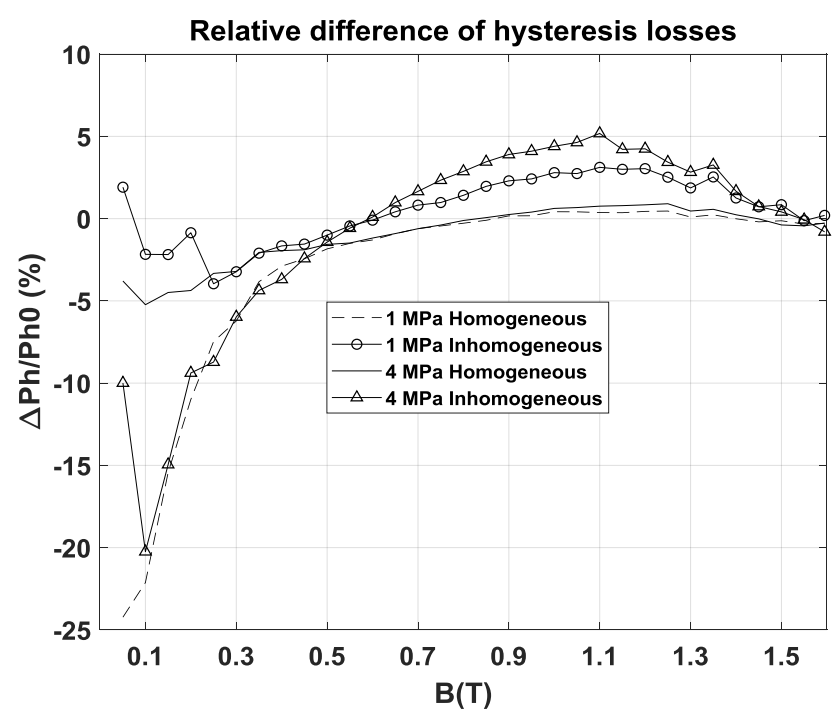

Figure 13 - Impact of the compressive stress on hysteresis losses and on excess losses 
One hypothesis based on our simulation and experimental results but also on physical considerations, is that the compressive stress in the thickness direction will induce stress in the laminations plane, for the inhomogeneous case. Indeed, Figure 14 and Table 2 give average Cauchy stress $(\sigma)$ along $\vec{e}_{r}, \vec{e}_{\theta}$ and $\vec{e}_{z}$ in different area of the magnetic circuit.

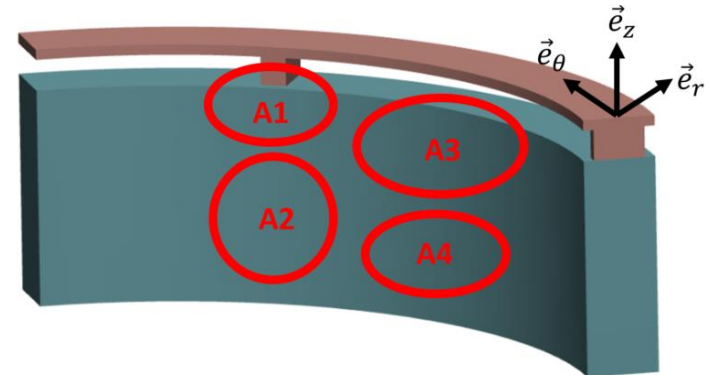

Figure 14 - Cylindrical coordinates and definition of areas

\begin{tabular}{|c|c|c|c|c|}
\hline $\begin{array}{c}\text { Global compressive stress } \\
\left(\text { along } \vec{e}_{z}\right)=\mathbf{1} \text { MPa }\end{array}$ & \multicolumn{2}{|c|}{ Homogeneous } & \multicolumn{2}{|c|}{ Inhomogeneous } \\
\hline $\begin{array}{c}\text { Maximum local stress } \\
\left(\text { along } \vec{e}_{z}\right)\end{array}$ & \multicolumn{2}{|c|}{-} & \multicolumn{2}{|c|}{$20 \mathrm{MPa}$} \\
\hline $\begin{array}{c}\text { Cauchy stress direction } \\
(\mathrm{MPa})\end{array}$ & $\vec{e}_{r}$ & $\vec{e}_{\theta}$ & $\vec{e}_{r}$ & $\vec{e}_{\theta}$ \\
\hline \multirow{4}{*}{\begin{tabular}{c} 
Average $\sigma$ on A1 $(\mathrm{MPa})$ \\
\cline { 3 - 4 }
\end{tabular}} & \multirow{4}{*}{$\sim 0$} & $\sim-1,5$ & $\sim-8$ \\
\cline { 1 - 1 } Average $\sigma$ on A2 $(\mathrm{MPa})$ & $\sim 0$ & $\sim 1$ \\
\hline Average $\sigma$ on A3 $(\mathrm{MPa})$ & & $\sim 0$ & $\sim 1,5$ \\
\hline Average $\sigma$ on A4 $(\mathrm{MPa})$ & & & $\sim 0$ & $\sim-1$ \\
\hline
\end{tabular}

Table 2. Cauchy stress in the magnetic circuit along $\vec{e}_{r}$ and $\vec{e}_{\theta}$ for homogeneous and inhomogeneous case

First, concerning the homogeneous case, the impact on magnetic properties seems to be only due to the compressive stress in the thickness direction. These modifications of magnetic properties may be related to magnetostriction effect [13], which could explain the fact that we observed decrease on hysteresis losses for low inductions, Figure 13. However, furthers studies need to be conducted in order to improve the understanding of magnetostriction effect along the height of the laminations. Second, our hypothesis concerning the observed differences on magnetic properties between homogeneous and inhomogeneous case is that, because of the airvent spacers, the compressive stress along $\vec{e}_{z}$ induces few stresses along $\vec{e}_{r}$ and more stresses along $\vec{e}_{\theta}$. This one is in compression (A1 and A4) and in traction (A2 and A3). It is known, in the literature, that tensile stress, in the flux direction and in elastic domain, could degrades or improves the magnetic properties and that the compressive stress degrades them [13], [14]. According to Table 2., compressive stress level is higher than the tensile one. The increase on iron losses and the degradation on normal B-H curves compared to the homogeneous case can be related to the induced compressive stress on $\vec{e}_{\theta}$ (A1). Nevertheless, as for the homogeneous case, further studies need to be conducted in order to improve the understanding of these phenomena.

\section{Conclusions}

The presented study deals with the effect on the magnetic properties of a compressive stress in the thickness direction of a lamination stack. Two stress configurations have been considered, homogeneous and inhomogeneous (due to airvent spacers). Experimental results show that in the second case, the impact on the magnetic properties is more significant due to higher local stresses. The magnetic behavior law is mainly degraded at average levels of magnetic flux density (in the knee region of the B-H curve). Moreover, the analyze of the iron loss by extracting the hysteresis loss contribution, showed that this latter is mostly impacted by the compressive stress at low and average magnetic flux density levels. Also, the observation of the impact on the global losses is not only explained by the impact on the hysteresis losses. This means that, under the assumption that classical losses are not modified by the stress level, the excess losses are also impacted by the compressive stress.

These results allow considering the design of large generators by including the effect of the lamination stack assembly with airvent spacers. This requires considering compressive 
stress in the material models. Additional experimental tests must be also carried out by varying the number of airvent spacers but also their shapes. Indeed, airvent spacers are located on the stator tooth and stator yoke as well, with an orientation either perpendicular or parallel to the path of the magnetic flux density.

Finally, this paper demonstrates the interest of studying the impact on magnetic properties of compression in the thickness direction of lamination stacks separated by airvents.

\section{References}

[1] M. Bali et A. Muetze, « Modeling the Effect of Cutting on the Magnetic Properties of Electrical Steel Sheets », IEEE Trans. Ind. Electron., vol. 64, n 3, p. 2547-2556, mars 2017.

[2] K. Bourchas et al., « Influence of cutting and welding on magnetic properties of electrical steels », in 2016 XXII International Conference on Electrical Machines (ICEM), 2016, p. 1815-1821.

[3] A. Schoppa, J. Schneider, C.-D. Wuppermann, et T. Bakon, « Influence of welding and sticking of laminations on the magnetic properties of non-oriented electrical steels », $J$. Magn. Magn. Mater., vol. 254-255, p. 367-369, janv. 2003.

[4] K. Yamazaki et W. Fukushima, « Loss Analysis of Induction Motors by Considering Shrink Fitting of Stator Housings », IEEE Trans. Magn., vol. 51, n 3, p. 1-4, mars 2015.

[5] D. Miyagi, Y. Aoki, M. Nakano, et N. Takahashi, «Effect of Compressive Stress in Thickness Direction on Iron Losses of Nonoriented Electrical Steel Sheet », IEEE Trans. Magn., vol. 46, nº 6, p. 2040-2043, juin 2010.

[6] K. Yamamoto and S. Yanase, « Magnetic properties of non-oriented electrical steels under compressive stress normal to their surface », Przeglad Elektrotechniczny, 2011.

[7] Y. Maeda et al., « Development of the apparatus for measuring magnetic properties of electrical steel sheets in arbitrary directions under compressive stress normal to their surface », AIP Adv., vol. 7, nº 5, p. 056664, mars 2017.

[8] N. Alatawneh, T. Rahman, D. A. Lowther, et R. Chromik, « Design and analysis of a toroidal tester for the measurement of core losses under axial compressive stress », $J$. Magn. Magn. Mater., vol. 432, p. 519-526, juin 2017.

[9] V. Manescu Paltanea, G. Paltanea, et H. Gavrila, «Energy Loss Analysis and Magnetic Properties of Non-Oriented Electrical Steel Cut through Different Technologies », Advanced Materials Research, 2015.

[10] SimScale Software, SimScale GmbH. 2019.

[11] 393-1991, «IEEE standard for test procedures for magnetic cores », IEEE Stand., 1992.

[12] J. D. Ferry, Viscoelastic Properties of Polymers. John Wiley \& Sons, 1980.

[13] G. H. Shirkoohi et A. J. Moses, «Effects of stress on magnetostrictive properties of low silicon non-oriented electrical steel », J. Magn. Magn. Mater., vol. 83, n 1, p. 177-178, janv. 1990.

[14] D. Miyagi, K. Miki, M. Nakano, et N. Takahashi, «Influence of Compressive Stress on Magnetic Properties of Laminated Electrical Steel Sheets », IEEE Trans. Magn., vol. 46, $\mathrm{n}^{\mathrm{o}} 2$, p. 318-321, 2010. 